\title{
DYNAMIC MODELING AND CONTROLLABILITY ANALYSIS OF DME PRODUCTION IN AN ISOTHERMAL FIXED BED REACTOR
}

\author{
M. Farsi* \\ Department of Chemical Engineering, School of Chemical and Petroleum Engineering, Shiraz \\ University, Shiraz 71345, Iran
}

Received 11 April 2014; received in revised form 20 March 2015

\begin{abstract}
In this study, to enhance Dimethyl Ether (DME) production from methanol dehydration, an isothermal fixed-bed reactor has been modeled heterogeneously against a commercial adiabatic reactor at dynamic condition. A sensitivity analysis has been carried out to evaluate the influence of input variables on the process conditions using considered dynamic model. The results of sensitivity analysis showed that the feed composition is the main input variable in this system. Also, the process controllability has been investigated using a conventional feedback PID controller. The outlet DME composition from the reactor and circulated boiling water pressure in the steam drum are selected as controlled and manipulated variables, respectively. The responses of the control system to disturbance rejection and setpoint tracking showed that the considered control structure can maintain the process at the desired condition.
\end{abstract}

Keywords: Dimethyl Ether; Heterogeneous Model; Methanol Dehydration; PID Controller.

Available online at http://www.Ganglajol.info/index.php/CERB

* To whom all correspondence should be addressed.

(email: farsi@shirazu.ac.ir) 


\section{Chemical Engineering Research Bulletin 17(2015) 40-51}

\section{INTRODUCTION}

Dimethyl ether as the simplest ether is a colorless gas at the ambient condition that is easily liquefied under light pressure. It does not produce any particulate matter and toxic gases such as $\mathrm{NO}_{\mathrm{x}}$ and $\mathrm{SO}_{\mathrm{x}}$ at burning [1]. It is useful for a variety of applications such as liquefied petroleum gas substitute, transportation fuel, fuel cell, solvent and propellant in various aerosol products [2].

DME can be produced from a variety of feed-stock such as natural gas, crude oil, coal, waste products and biomass [3]. Recently, biomass is recognized as an extensive feedstock to produce synthesis gas and consequently DME production [4]. Although the commercial technology for DME production is methanol dehydration in conventional reactors, many researchers have focused on the direct conversion of synthesis gas to DME in a single step process [5]. Methanol dehydration can be occurred in a slurry reactor because of the better heat removal capability by coil or jacket and higher catalyst surface area due to small catalyst particle size. However, slurry reactors suffer from significant mass transfer resistance due to use of inert liquid phase [6]. At the present, DME is commercially produced through methanol dehydration using acidic porous catalysts [7]. Due to simplicity and lower capital cost, adiabatic fixed bed reactors are the first choice for catalytic reactions which have low or intermediate reaction heat [8]. However, in case of highly endothermic or exothermic reactions, the catalyst sintering and deactivation may happen [9]. Sintering is a solid state transformation of catalyst, which occurs at high temperatures and is promoted by water vapor molecules. In spite of catalyst loss in fluidized reactors due to collision between catalyst particles and the reactor wall, the fluidized bed reactor has been suggested as a perfect reactor for DME synthesis $[10,11]$.

There are several articles in the literature that discuss modeling of catalytic packed bed reactors. Shahrokhi et al. modeled a fixed-bed reactor for methanol production from synthesis gas at dynamic state and proposed an optimizer to maximize methanol production rate [12]. Jahanmiri and Eslamloueyan modeled a low pressure methanol reactor and showed that the difference between one and two-dimensional model in negligible [13]. Also, they calculated the optimal shell side temperature considering methanol production as objective function. Lee et al. modeled DME production from synthesis gas in a fixed-bed reactor at steady state condition [14]. Farsi et al. modeled an industrial adiabatic methanol dehydration reactor to DME production at dynamic condition and investigated the controllability of the considered process [15]. Omata et al. studied DME production from synthesis gas in a temperature gradient reactor to overcome the both equilibrium limitations and catalyst activity, experimentally [16]. Then, they optimized the reactor operating condition for higher $\mathrm{CO}$ conversion by combining genetic algorithm and neural network. Farsi et al. proposed an optimized isothermal reactor for large scale DME production from crude methanol [17]. They optimized the proposed reactor at steady state condition. The results showed that isothermal reactor is more efficient compared to the traditional adiabatic reactor. Farsi et al. modeled and optimized the isothermal membrane fixed bed reactor for DME production from methanol dehydration [18]. The simulation results of the membrane reactor indicated that the methanol conversion is improved about $6.2 \%$ compared to the conventional reactor. 
The main objective of the process control is to control the required product rate and concentration at the desired level. Fixed bed reactors are a nonlinear distributed parameter system with dead time that are more difficult to control [19]. Jorgensen presented a good review for dynamic modeling and control of fixed bed reactors [20]. Aguilar et al. developed a robust PID control to control the temperature of a fluid catalytic cracking reactor [21]. This control strategy was robust against model uncertainties and noisy measurements.

Mainly, the objective of this paper is dynamic modeling, simulation and control of an isothermal DME synthesis reactor that has been coupled with a steam drum. In this study, a dynamic one-dimensional heterogeneous model is developed to simulate the isothermal reactor based on the mass and energy conservation laws. Also, to verify the accuracy of the proposed model and considered assumptions, results of the steady state model of adiabatic reactor are compared with the design data (Petrochemical Zagros Complex in Iran). Then, a conventional feedback control system is designed to maintain the outlet DME concentration at the desired value.

\section{MODELING}

The main operations in the DME process are the feed preparation, DME synthesis convertor, product separation and methanol recycling. Figure 1 shows the process flow sheet of DME synthesis in an isothermal fixed bed reactor. The isothermal fixed bed reactor is a vertical shell and tube heat exchanger, which tubes are packed with catalyst pellets and surrounded by the boiling water. The heat of reaction is removed from the reactor by circulating the boiling water as coolant in the shell side of the reactor. The outlet coolant from the reactor is passed through a steam generator, and then recycled to the shell side of the reactor.

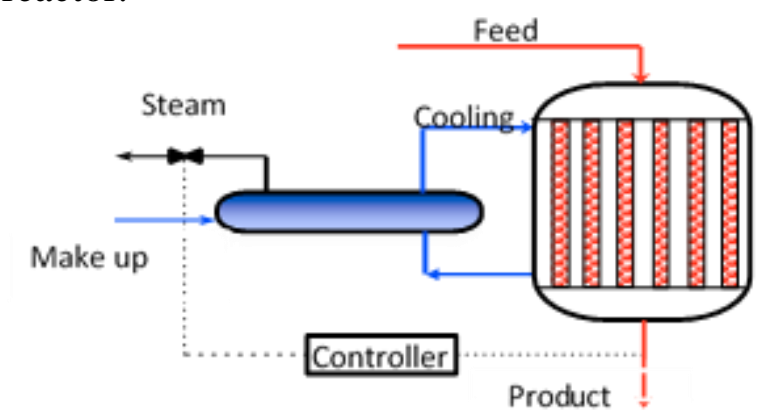

Figure 1: Process Flow Diagram of DME Production

\section{Reaction Kinetics}

The reaction of DME synthesis is mainly dehydration of methanol that is an exothermic and equilibrium reaction. Many researches have focused on DME synthesis through methanol dehydration and synthesis gas conversion [22-24]. The reaction equation of DME synthesis from dehydration of methanol is as the following.

$2 \mathrm{CH}_{3} \mathrm{OH} \Leftrightarrow \mathrm{CH}_{3} \mathrm{OCH}_{3}+\mathrm{H}_{2} \mathrm{O} ; \Delta \mathrm{H}_{298}=-23.4 \mathrm{KJ} / \mathrm{mol}(1)$

In this work, the rate expressions have been selected from the kinetic model proposed by Berćić et al. [25].

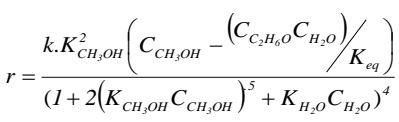

where,

$\operatorname{Ln}\left(K_{\text {cq }}\right)=0.86 \log T+\frac{3138}{T}+1.33 \times 10^{-3} T-1.23 \times 10^{-5} T^{2}+3.5 \times 10^{-10} T$

$K_{\mathrm{CH} 3 \mathrm{OH}}$ and $K_{\mathrm{H} 2 \mathrm{O}}$ are the reaction rate constant and the adsorption equilibrium $\mathrm{k}_{1}$, constants for methanol and water vapor, respectively, which has been tabulated in Table 1. Commercially, $\gamma-\mathrm{Al}_{2} \mathrm{O}_{3}$ catalyst is used in methanol dehydration reaction. 
Table 1: Kinetic and Equilibrium Constants

\begin{tabular}{|l|l|l|}
\hline \multicolumn{1}{|c|}{ Parameter } & \multicolumn{1}{c|}{$\mathbf{A}_{\mathbf{i}}$} & \multicolumn{1}{c|}{$\mathbf{B}_{\mathbf{i}}$} \\
\hline $\mathrm{K}_{0}$ & $3.7 \mathrm{e} 10$ & -105000 \\
\hline $\mathrm{K}_{\mathrm{H} 2 \mathrm{O}}$ & $0.84 \mathrm{e}^{-1}$ & 41100 \\
\hline $\mathrm{K}_{\mathrm{CH} 3 \mathrm{OH}}$ & $7.9 \mathrm{e}^{-4}$ & 7050 \\
\hline
\end{tabular}

\section{Process Modeling}

\section{Reactor Modeling}

In this study, a one-dimensional heterogeneous model has been considered to simulate DME reactor and steam drum at steady state and dynamic condition. The basic structure of the model is composed of heat and mass conservation equations coupled with thermodynamic and kinetic relations as well as auxiliary correlations to predict physical properties. In the process modeling the following assumptions have been considered.

- Plug flow pattern and negligible concentration and temperature gradient in radial direction.

- The bed void fraction is constant along the reactor.

- Uniform temperature in the catalyst pellet.

- Bed porosity in axial and radial directions is constant.

- The gas mixture is an ideal gas.

- Heat losses via surrounding is neglected

Thus, mass and energy balances for the gas phase are expressed by:

$\varepsilon \frac{\partial C_{i}}{\partial t}=-u_{s} \frac{\partial C_{i}}{\partial z}-k_{g i} a_{v}\left(C_{i}-C_{i s}^{s}\right)$

$\rho_{g} c_{p g} \varepsilon \frac{\partial T}{\partial t}=-u_{s} \rho_{g} c_{p} \frac{\partial T}{\partial z}+h_{f} a_{v}\left(T_{s}^{s}-T\right)-\frac{(\pi D) U}{A_{c}}\left(T-T_{j}\right)$

The mass and energy balances for the solid phase are expressed by:

$$
\begin{aligned}
& (1-\varepsilon) \frac{\partial C_{i}}{\partial t}=-k_{g i} a_{v}\left(C_{i}-C_{i s}^{s}\right)+\eta_{i} \rho_{B} r_{i} \\
& \rho_{B} c_{p s}(1-\varepsilon) \frac{\partial T_{s}}{\partial t}=-h_{f} a_{v}\left(T_{s}^{s}-T\right)-\eta_{i} \rho_{B}(-\Delta H) r_{i}
\end{aligned}
$$

The pressure drop in the catalytic packed bed is calculated by Ergun equation [26]:

$-\frac{\Delta p}{L}=150 \frac{(1-\varepsilon)^{2} \mu \cdot u_{c}}{d^{2} \varepsilon^{3}}+1.75 \frac{(1-\varepsilon) \rho \cdot u_{c}^{2}}{d . \varepsilon^{3}}$

The feed condition, characteristics of the catalyst pellets and the reactor design specifications of DME reactor is reported in Table 2 [20].

Table 2: Feed Specification and Reactor Data

\begin{tabular}{|c|c|}
\hline $\begin{array}{c}\text { Feed Composition } \\
\text { (Mole Fraction) }\end{array}$ & \\
\hline $\mathrm{CH}_{3} \mathrm{OH}$ & 0.94 \\
\hline $\mathrm{DME}$ & 0.05 \\
\hline $\mathrm{H}_{2} \mathrm{O}$ & 0.01 \\
\hline $\begin{array}{l}\text { Total molar flow rate } \\
\left(\mathrm{kmol} \mathrm{hr}^{-1}\right)\end{array}$ & 5600 \\
\hline Inlet temperature $(\mathrm{K})$ & 533 \\
\hline Inlet pressure (bar) & 18.18 \\
\hline Catalyst particle & $0.3175 \times 10^{-2}$ \\
\hline Particle diameter $(\mathrm{m})$ & 673 \\
\hline $\begin{array}{c}\text { Specific surface area } \\
\left(\mathrm{m}^{2} \mathrm{~m}^{-3}\right)\end{array}$ & \\
\hline Adiabatic reactor & 8 \\
\hline Reactor length $(\mathrm{m})$ & 4 \\
\hline Reactor diameter $(\mathrm{m})$ & 8 \\
\hline Isothermal reactor & 0.09 \\
\hline Reactor length $(\mathrm{m})$ & 2000 \\
\hline Tube diameter $(\mathrm{m})$ & \\
\hline Tube number & \\
\hline
\end{tabular}

Auxiliary equations are used to predict the model parameters. In the heterogeneous models physical properties of components and overall mass and heat transfer coefficients between catalyst solid phase and gas phase should be considered. In the mass 
and energy balance equations, $\eta_{i}$ is the effectiveness factor which is defined as the actual reaction rate per particle to theoretical reaction rate based on the external pellet surface concentration. The effectiveness factor is calculated from the dusty gas model [27]. The detail of dusty gas model is given in Appendix A. The methods used for calculating the physical properties, overall heat and mass transfer coefficients between solid and gas phase and mass diffusion needed for simulation are given in Table 3.

Table 3. Methods Used for Calculating the Physical Properties, Heat and Mass Transfer Coefficients

\begin{tabular}{|l|c|}
\hline \multicolumn{1}{|c|}{ Parameter } & Reference \\
\hline $\begin{array}{l}\text { Mass transfer } \\
\text { coefficient }\end{array}$ & Cussler [28] \\
\hline $\begin{array}{l}\text { Binary diffusion } \\
\text { coefficient }\end{array}$ & Reid et al. [29] \\
\hline $\begin{array}{l}\text { Gas conductivity } \\
\text { Effective diffusion } \\
\text { coefficient in pellet }\end{array}$ & [30] \\
\hline $\begin{array}{l}\text { Mixed gas heat } \\
\text { capacity }\end{array}$ & Ideal gas [32] \\
\hline $\begin{array}{l}\text { Gas viscosity } \\
\text { Gas-solid heat transfer } \\
\text { coefficient }\end{array}$ & Lucas [32] \\
\hline
\end{tabular}

\section{Steam Drum Modeling}

The steam drum is one of the most important components in a water cooled isothermal reactor. To develop a steam drum model, the following assumptions are made:

- Heat losses via surrounding is neglected

- In energy balance, pseudo-steady state condition is considered for vapor phase

The dynamic of this process can be described by the following set of mass and energy balance equations for liquid and vapor phases [28]. The schematic diagram of the steam drum is shown in Figure 2.

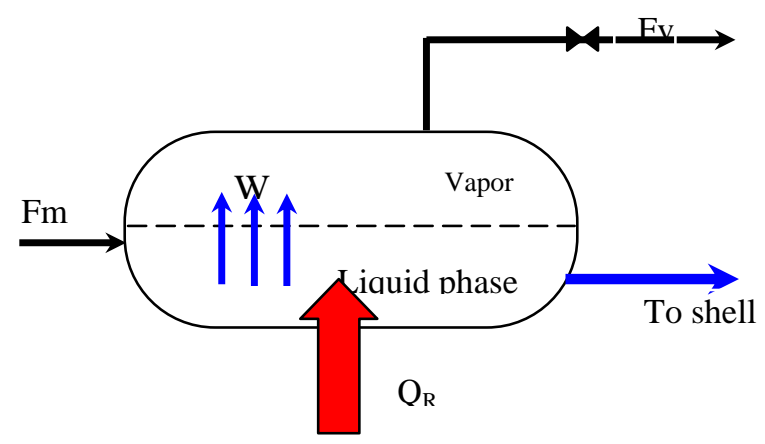

Figure 2: Schematic of the Control Structure for Isothermal Reactor

Subject to these assumptions, the gas and liquid mass balances are expressed by:

$$
\begin{aligned}
& \frac{d\left(\rho_{l} V_{l}\right)}{d t}=\rho_{m} V_{m}-w \\
& \frac{d\left(\rho_{v} V_{v}\right)}{d t}=w-\rho_{v} V_{v}
\end{aligned}
$$

The liquid energy balances is expressed by:

$$
C_{p} \frac{d\left(\rho_{l} V_{l} T\right)}{d t}=\left(\rho_{m} F_{m}\right) h_{m}-w h_{s}+Q_{R}
$$

\section{Numerical Solution}

To solve the set of nonlinear partial differential equations (PDEs) obtained from dynamic modeling, the reactor length is divided into equal discrete intervals. Then, using finite difference method the PDEs are converted into a set of ordinary differential equations (ODEs) in the time domain. The set of reactor and steam drum equations are solved by 4th order Runge-Kutta [35]. Before carrying out dynamic simulation, the initial condition of the system should be obtained using steady state equations. The objective of the steady state simulation of the DME reactor is to determine the concentration and temperature profiles along the reactor in normal operation. After 
rearranging the modeling equations for the steady state condition, a set of ordinary differential equation is obtained. This set of equations was solved by the method of 4 th order Runge-Kutta.

\section{Control Structure}

The main objective of control systems in industrial processes is to maintain the operating condition at the optimum state in spite of disturbances and uncertainties. The considered control structure in the DME process is shown in Figure 2. In this study, a conventional feedback PID controller has been used to investigate the load rejection and setpoint tracking tasks. In this configuration, the outlet DME mole fraction is controlled considering the circulating boiling water pressure as the manipulated variable. The heated coolant is passed through a steam generator to produce steam and recycled to the shell side of the reactor.

\section{RESULTS AND DISCUSSION}

\section{Steady State Simulation}

In this section, the steady state simulation results of the isothermal DME reactor have been presented. The model of methanol dehydration is validated against design data of a conventional adiabatic DME synthesis reactor. Table 4 shows the absolute errors between the simulation results and available plant data. The simulation results show that the proposed model is capable to predict concentration and temperature profiles along the adiabatic reactor with a high accuracy.

The validation of the isothermal reactor is impossible due to lack of data for the isothermal reactor. In this section, the steady state results of simulation, such as temperature and concentration profiles, in the isothermal reactor are presented. Figure
3 illustrates the molar flow rate of DME, methanol and water vapor along the isothermal reactor at steady state condition.

Table 4: Comparison of the Steady State Simulation Results of the Adiabatic Reactor with Plant Data

\begin{tabular}{|c|c|c|c|}
\hline & $\begin{array}{c}\text { Simulation } \\
\text { Result }\end{array}$ & $\begin{array}{c}\text { Plant } \\
\text { Data }\end{array}$ & A.R.E \\
\hline $\begin{array}{c}\text { Outlet DME } \\
(\mathrm{kmol} / \mathrm{hr})\end{array}$ & 2457 & 2506 & $1.95 \%$ \\
\hline $\begin{array}{c}\text { Outlet } \\
\mathrm{MeOH} \\
(\mathrm{kmol} / \mathrm{hr})\end{array}$ & 940.6 & 937.7 & $0.31 \%$ \\
\hline $\begin{array}{c}\text { Exit temp } \\
\left({ }^{\circ} \mathrm{C}\right)\end{array}$ & 652.2 & 644 & $1.27 \%$ \\
\hline
\end{tabular}

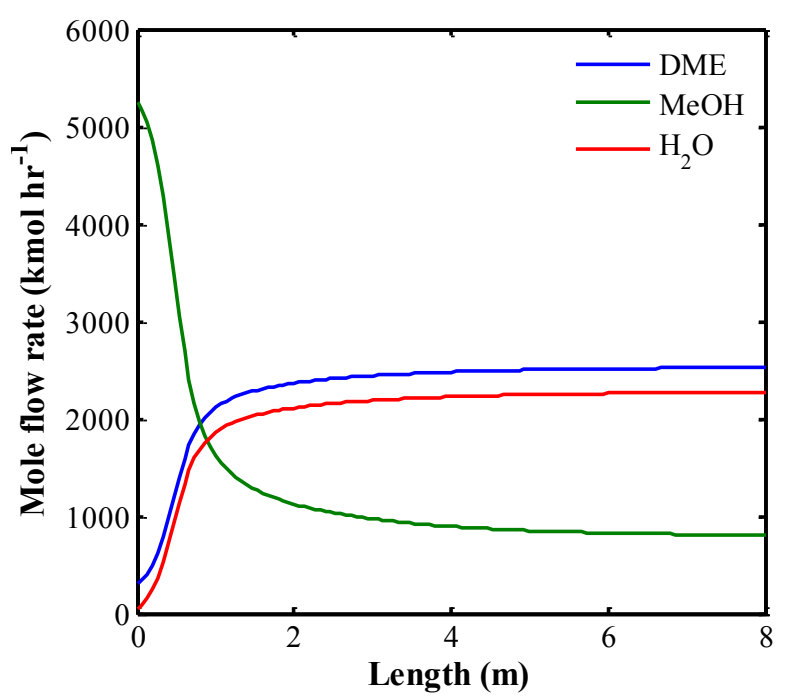

Figure 3: The Profiles of Mole Flow Rates of DME, Methanol and Water along the Reactor

DME mole fraction along the reactor in the solid and gas phases predicted by the heterogeneous model has been compared in Figure 4. In the second half of the reactor, where the reaction approaches to the equilibrium, the difference between gas and solid phase concentrations is negligible. 


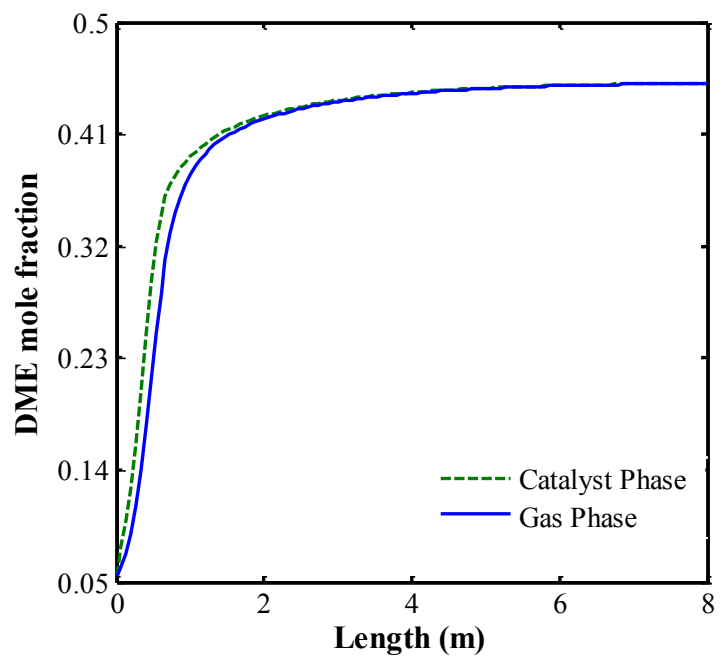

Figure 4: DME Mole Fraction in Solid and Gas phase

The predicted temperature profile along the reactor is shown in Figure 5. According to Le Châtelier's principle, temperature reduction in the second half of the isothermal reactor leads to shift the methanol dehydration reaction in the exothermic direction, which results the higher DME production. At the reactor entrance, temperature increases rapidly and results increasing kinetic constant of reaction rate. In the isothermal reactor, after a certain position along the reactor the temperature maintains constant due to heat transfer between exothermic reaction and boiling water through the tube wall.

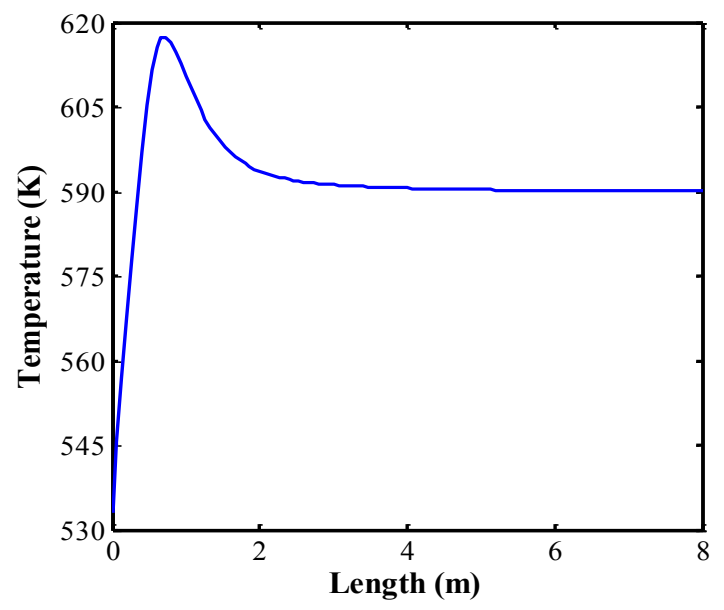

Figure 5: Predicted Temperature Profile along the Reactor

\section{Open Loop Dynamic Simulation}

Dynamic simulation is mainly used to investigate the process stability, safety and controllability. To investigate the influence of input variables on the dynamic behavior of DME reactor, feed temperature, feed pressure and composition have been considered as the main loads in the system. In this section, the effect of $\pm 10^{\circ} \mathrm{C}$ step change in the feed temperature on the outlet DME mole flow rate is presented in Figure 7. This figure shows that the outlet DME mole flow rate from the reactor reaches to a new steady state condition after 40 seconds. Since the optimal temperature of shell side is inserted in the simulation (590K), DME production decreases with variation of feed temperature in this configuration. This process exhibits inverse response behavior due to integration of kinetic constant and equilibrium limitations. Due to these disturbances in the feed temperature, the outlet DME mole flow rate has changed less than $10 \mathrm{kmol} \mathrm{hr}^{-1}$.

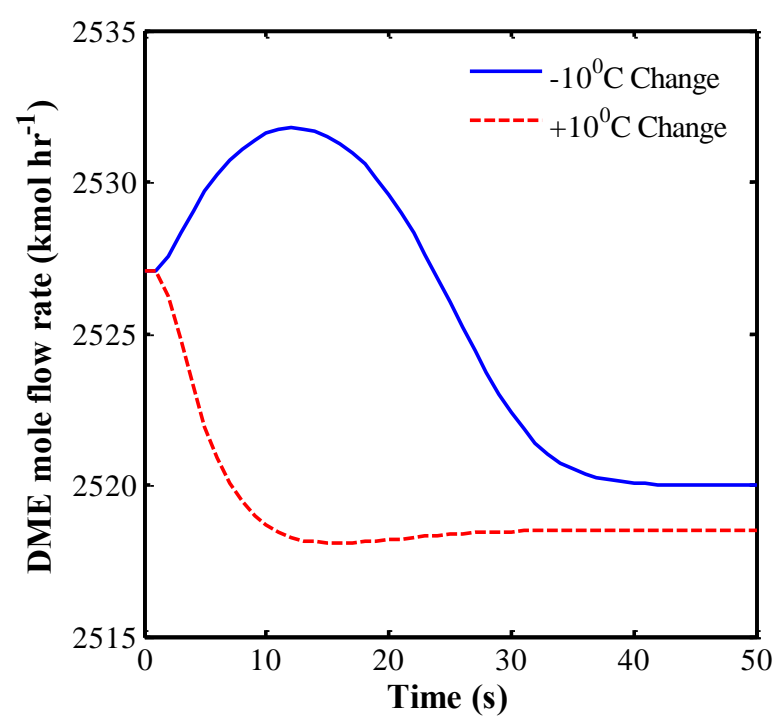

Figure 6: The Outlet DME Mole Flow Rate Profile from the Reactor to $\pm 10^{\circ} \mathrm{C}$ Step Change in the Shell Side Temperature

In the literature, the expression of "inverse response" is used for processes that have an initial response direction opposite to 
the final direction. These processes are difficult to be identified and controlled due to the presence of right half plane zeros. According to Le Châtelier's principle, changing an independent variable of a system at equilibrium such as temperature, pressure and concentration, shifts the equilibrium toward that tends to reduce the effect of the change. Thus, when the inlet pressure of the DME synthesis reactor is changed, the equilibrium remains constant due to equimolar stoichiometry in the methanol dehydration reaction. Consequently, the effect of feed pressure variation on DME production isn't presented. The feed composition effect is studied considering -0.05 step changes in the methanol mole fractions and +0.05 step changes in the water vapor mole fraction. This disturbance in the mole fraction is feasible and reasonable in industrial scale. Figure 7 shows the outlet DME mole flow rate profile with the passage of time. According to Le Châtelier's principle, decreasing the feed composition shifts thermodynamic equilibrium to neutralize this effect by decreasing methanol conversion. Due to these variations in the feed composition, the outlet DME mole flow rate decreases about $60 \mathrm{kmol} \mathrm{hr}^{-1}$. This figure shows that the process has a time delay about 20 second. The most of industrial processes, particularly distributed systems such as tubular reactors, exhibit time delays or dead times. Generally, dead time reduces the controller system ability and performance.

The results in Figure 7 indicate that the feed composition is the major disturbance that should be rejected by the designed control system. In this process, maintaining DME production rate at the desired level is possible using variation of circulating saturated water pressure in the shell side as the manipulated variable inserting a conventional control valve.

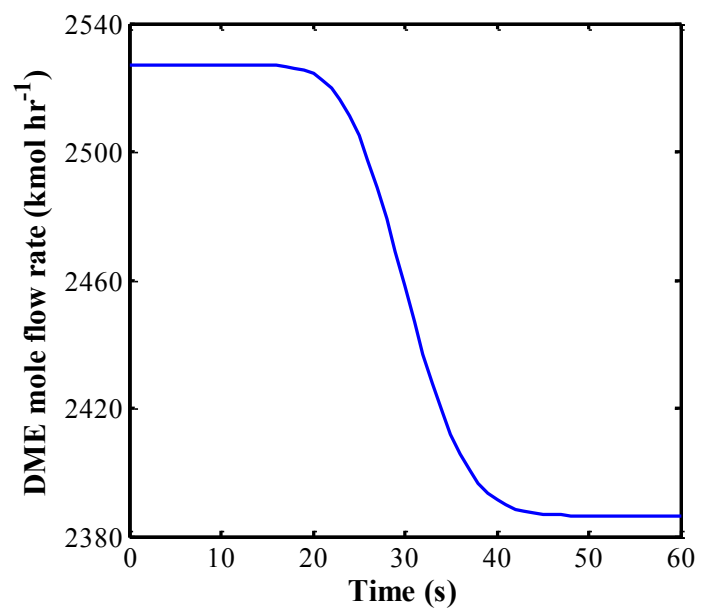

Figure 7: The outlet DME Mole Flow Rate Profile from the Reactor to \pm 0.05 Step Change in Feed Mole Fractions

\section{Closed Loop Process Simulation}

In order to control the outlet DME mole flow rate at the desired level a feedback control loop is designed based on the conventional PID (Proportional-IntegralDerivative) controller. The PID feedback controller is widely used in industries, because it requires minimal process knowledge to design and controller tuning is simple [36]. A properly tuned PID controller can be robust against disturbances and uncertainty. In this study, the PID controller has been tuned using Closed Loop ZieglerNichols method. This algorithm is one of the most common methods for tuning PID controllers. The parameters of the controller, i.e. the proportional gain, reset time and derivative value are derived from the ultimate gain and the sustained period of oscillation [37]. According to this procedure, the controller gain, reset time and derivative constant has been calculated about 12, $0.45 \mathrm{~min}$ and $0.08 \mathrm{~min}$, respectively. In this section, the dynamic closed-loop behavior of the process to predefined disturbances and set point variation are presented and analyzed. 


\section{Load Rejection}

The considered control system should be capable to reject process disturbances using available manipulated variable without saturation of the control valve. To investigate the performance of the proposed control structure in disturbance rejection, 0.02 and +0.02 step change in the inlet methanol and DME mole fraction has been introduced as the main disturbance. Figure 8 shows the closed loop response of the process due to this disturbance. As can be seen from this figure, the considered load is completely rejected after about 5 minutes using the tuned conventional PID controller and process output approached to the desired setpoint. Also, although the overshoot of the controller response is almost high, the decay ratio, which states how oscillations decay in a system, is negligible. Thus, the response of the considered PID controller is acceptable in the load rejection.

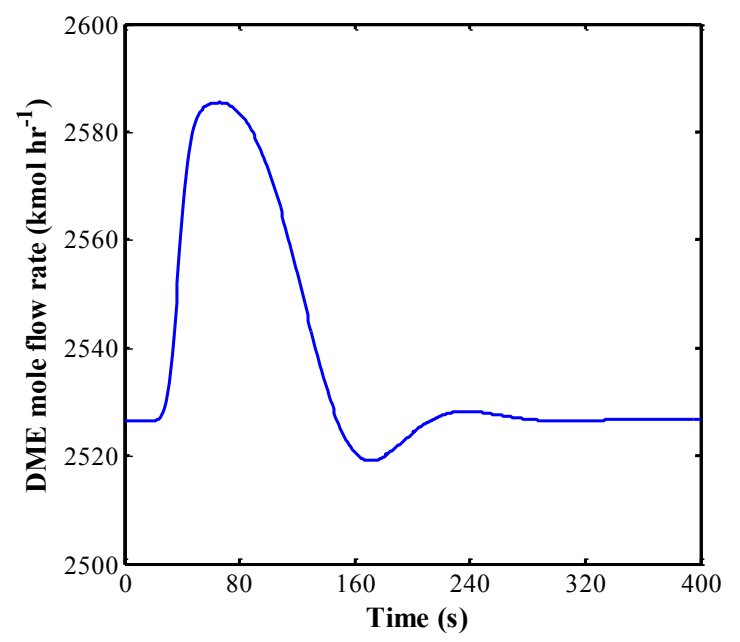

Figure 8: Closed Loop Response for \pm 0.02 Step Change in the Feed Mole Fraction

\section{Setpoint Tracking}

In case of servo tracking, the considered control loop should be capable to track the process setpoint using available manipulated variable without saturation of the control valve. The ability of the proposed control system to track setpoint has been investigated considering -0.02 step changes in the process setpoint. Figure 9 shows the efficiency of considered control loop to track the desired outlet DME mole flow rate.

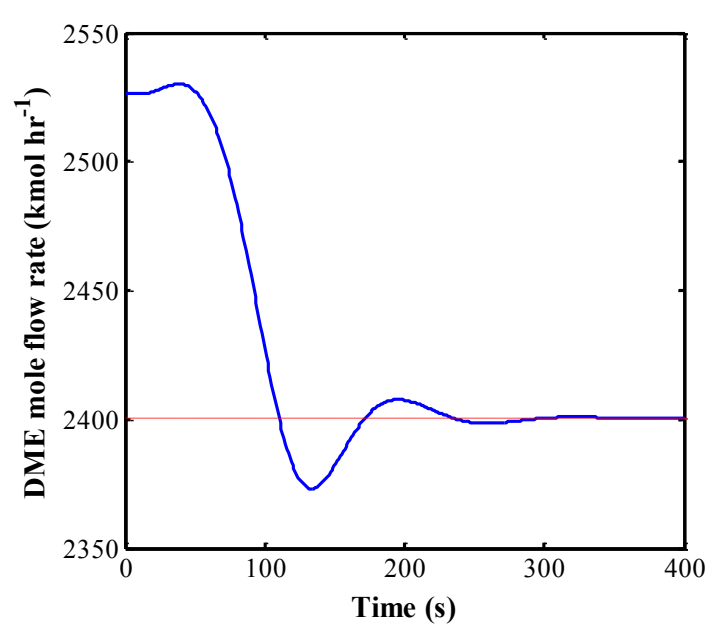

Figure 9: Closed Loop Response for -0.02 Step Change in Setpoint

Decreasing shell side temperature reduces outlet methanol mole flow rate and process approaches to the new setpoint. In this configuration, the outlet DME mole flow rate approaches to the new setpoint after 5 min. Decreasing shell side temperature is occurred using shell side pressure reduction with common control valves. Table 5 presents the dynamic characteristics of the control loop response for the set point tracking. In this system, the overshoot and particularly decay ratio are almost small which result low oscillation of the control system. This table shows that characteristics of considered PID controller are acceptable in the servo tracking.

Table 5: Dynamic Properties of the Closed Loop Response for Setpoint Tracking

\begin{tabular}{|l|c|}
\hline Overshoot & \% 26 \\
\hline Decay ratio & $\% 12$ \\
\hline Settling time $(\mathrm{sec})$ & 285 \\
\hline
\end{tabular}




\section{CONCLUSION}

In this study, methanol dehydration in an isothermal DME synthesis reactor was modeled and simulated, dynamically. A onedimensional heterogeneous model was considered based on the mass and energy conservation laws. The results of steady state simulation of the adiabatic model were compared to the industrial plant data. This comparison showed a good agreement between the simulation results and plant data. Open loop responses of the process against important disturbances were investigated to discover the dynamic properties of the process. These results showed that the process has reverse response due to integration of reaction, heat transfer and equilibrium limitations. To maintain the methanol production rate at the desired setpoint and process safety, a tuned PID controller was used considering cooling water pressure as manipulated variable. The performance of considered feedback closed loop system was investigated for disturbance rejection and setpoint tracking. The dynamic properties of the control system indicated that this configuration has good performance in the load rejection and servo problem.

\section{REFERENCES}

[1] Semelsberger TA, Borup RL, Greene $H L$, Dimethyl ether (DME) as an alternative fuel, Journal of Power Sources, 2006. 156(2): 497-511.

[2] Galvita VV, Semin GL, Belyaev VD, Yurieva TM, Sobyanin VA, Production of hydrogen from dimethyl ether, Applied Catalyst, 2001. 216(1-2): 8590.

[3] Arcoumanis C, Bae C, Crookes R, Kinoshita E, The potential of dimethyl ether $(D M E)$ as an alternative fuel for compression-ignition engines: $A$ review, Fuel, 2008. 87: 1014-1030.
[4] Pengmei L, Zhenhong $Y$, Chuangzhi W, Longlong $M$, Yong $C$, Noritatsu T, Bio-syngas production from biomass catalytic gasification, Energy Convers. Manag., 2007. 48: 11321139.

[5] $\mathrm{Ng} \mathrm{KL}$, Chadwick D, Toseland BA, Kinetics and modeling of dimethyl ether synthesis from synthesis gas, Chem. Eng. Sci., 1999. 54: 3587-3592.

[6] Guo JW, Niu YQ, Zhang BJ, Macro kinetics study on DME synthesis from syngas in slurry reactor, Natural Gas Chemical Industry, 2000. 25: 4-7.

[7] Lu WZ, Teng LH, Xiao WD, Simulation and experiment study of Dimethly ether synthesis from syngas in a fluidized-bed reactor, Chem. Eng. Sci., 2004. 59: 5455-5464.

[8] Froment GF, Bischoff KB, Chemical Reactor Analysis and Design, John Wiley \& Sons, New York, 1990.

[9] Fogler HS, Elements of chemical reaction engineering, Prentice-Hall, New York,1992.

[10] Ray YC, Jiang TS, Wen CY, Particle attrition phenomena in a fluidized bed, Powder Technology, 1987. 49(3): 193-206.

[11] Petukhov $Y$, Kalman H, A new apparatus for particle impact tests, Particle and Particle Systems Characterization, 2003. 20(4): 267275.

[12] Shahrokhi M, Baghmisheh GR, Modeling, simulation and control of a methanol synthesis fixed-bed reactor, Chem. Eng. Sci., 2005. 60(15): 42754286.

[13] Jahanmiri A, Eslamlueyan R, Optimal Temperature Profile in Methanol Synthesis Reactor, Chem. Eng. Communication, 2002. 189(6): 713741.

[14] Lee SB, Cho W, Park DK, Yoon ES, Simulation of fixed bed reactor for 
dimethyl ether synthesis, Korean J. Chem. Eng., 2006. 23(4): 522-530.

[15] Farsi M, Eslamloueyan R, Jahanmiri $A$, Modeling, simulation and control of dimethyl ether synthesis in an industrial fixed-bed reactor, Chem. Eng. Proc., 2010. 50(1): 85-94.

[16] Omata K, Ozaki T, Umegaki T, Watanabe $Y$, Nukui N, Yamada M, Optimization of the temperature profile of a temperature gradient reactor for DME synthesis using a simple genetic algorithm assisted by a neural network: High-quality transportation fuels, Energy \& fuels, 2003. 17(4): 836-841.

[17] Farsi M, Jahanmiri A, Eslamloueyan $R$, Modeling and Optimization of $\mathrm{MeOH}$ to DME in Isothermal Fixedbed Reactor, Int. J. Chem. Reac. Eng., 2010. 8: A79.

[18] Farsi M, Jahanmiri A, Enhancement of DME Production in an Optimized Membrane Isothermal Fixed-Bed Reactor, Int. J. Chem. Reac. Eng., 2011. 9: A74.

[19] Assaf EM, Giordano RC, Nascimento $C A O$, Thermal runaway of ethylene oxidation reactors: prevision through neural network, Chem. Eng. Sci., 1996. 51(11): 3107-3112.

[20] Jorgensen SB, Fixed bed reactor dynamics and control- a review, In: proceedings of the IFAC Control of a Distillation Columns and Chemical Reactors, Oxford, 1986.

[21] Aguilara R, Poznyakb A, MartinezGuerrab $R, \quad$ Maya-Yescasc $R$, Temperature control in catalytic cracking reactors via a robust PID controller, Journal of Process Control, 2002. 12(6): 695-705.

[22] Xu M, Goodman DW, Bhattacharyya A, Catalytic dehydration of methanol to dimethyl ether (DME) over Pd/Cab-
O-Sil catalysts, applied catalysis A: General, 1997. 149: 303-309.

[23] Jun KW, Lee HS, Roh HS, Park AE, Catalyst dehydration of methanol to dimethyl ether (DME) over solid-acid catalysts, Bull. Korean Chem. Soc., 2006. 23(6): 803-806.

[24] Bondiera j, Naccache C, Kinetics of Methanol Dehydration in Dealuminated H-Mordenite: Model with Acid and Basic Active Centers, Applied Catalysis, 1991. 69: 139-148.

[25] Berćić G, Levec J, Intrinsic and global reaction rate of methanol dehydration over Al2O3 pellets, Ind. Eng. Chem. Res., 1992. 31: 1035-1040.

[26] Richardson JF, Harker JH, Backhurst $J R$, Chemical Engineering, Vol. 2, Butterworth-Heinemann, 1999.

[27] Graaf GH, Choltens H, Tamhuis HJ, Beenackers AACM, Intra-particle diffusion limitations in low-pressure methanol synthesis, Chem. Eng. Sci., 1990, 45(4): 773-783.

[28] Cussler EL, Diffusion, Mass Transfer in Fluid Systems, Cambridge University Press, United Kingdom, 1984.

[29] Reid RC, Sherwood TK, Prausnitz J, The Properties of Gases and Liquids, McGraw-Hill, New York, 1977.

[30] Lindsay AL, Bromley LA, Thermal conductivity of gas mixture, Ind. Eng. Chem., 1950, 42: 1508-1510.

[31] Wilke CR, Estimation of liquid diffusion coefficients, Chem. Eng. Progress, 1949. 45, 218-224.

[32] Poling BE, Prausnitz JM, O'Connell $J P$, The Properties of Gases \& Liquids, McGraw-Hill, New York, 2001.

[33] Smith JM, Chemical Engineering Kinetics, McGraw-Hill, New York, 1980.

[34] Luyben WL, Process Modeling, Simulation and Control for Chemical 


\section{Chemical Engineering Research Bulletin 17(2015) 40-51}

Engineering, McGraw-Hill, New York, 1986.

[35] Dormand JR, Prince PJ, A family of embedded Runge-Kutta formulae, J. Comp. Appl. Math., 1980. 6: 19-26.

[36] Richards JR, Congalidis JP, Measurement and control of polymerization reactors, Computers \& Chemical Engineering, 2006. 30: 1447-1463
[37] Phillips CL, Harbor RD, Feedback Control Systems, Prentice Hall, New Jersey, 2000.

[38] Skrzypek J, Grzesik M, Szopa R, Theoretical analysis of two parallel and consecutive reactions in isothermal symmetrical catalyst pellets using a dusty-gas model, Chem. Eng. Sci., 1984. 39: 515-521.

[39] Jackson R, Transport in porous catalysts, Elsevier, Amsterdam, 1977.

Available online at http://www.banglajol.info/index.php/CERB 